EGU21-14901

https://doi.org/10.5194/egusphere-egu21-14901

EGU General Assembly 2021

(c) Author(s) 2021. This work is distributed under

the Creative Commons Attribution 4.0 License.

\title{
On the imprint of the mesoscale organization of tradewind clouds at cloud base and below
}

Sandrine Bony, Pierre-Etienne Brilouet, Patrick Chazette, Pierre Coutris, Julien Delanoë, Marie Lothon, Nicolas Rochetin, Alfons Schwarzenboeck, and Bjorn Stevens

LMD/IPSL, CNRS, Sorbonne University, Paris, France (bony@Imd.jussieu.fr)

Trade-wind clouds can exhibit different patterns of mesoscale organization. These patterns were observed during the EUREC ${ }^{4} \mathrm{~A}$ (Elucidating the role of cloud-circulation coupling in climate) field campaign that took place in Jan-Feb 2020 over the western tropical Atlantic near Barbados: while the HALO aircraft was observing clouds from above and was characterizing the large-scale environment with dropsondes, the ATR-42 research aircraft was flying in the lower troposphere, characterizing clouds and turbulence with horizontal radar-lidar measurements and in-situ probes and sensors. By analyzing these data for different cloud patterns, we investigate the extent to which the cloud organization is imprinted in cloud-base properties and subcloud-layer heterogeneities. The implications of our findings for understanding the roots of the mesoscale organization of tradewind clouds will be discussed. 